\title{
Penataan Ulang Layout area Rekondisi Komponen Engine Guna Mencapai Efisiensi Proses Kerja Di Workshop PT. "X" Balikpapan
}

\author{
Syahruddin, S.Pd. MT \\ Jurusan Teknik Mesin Alat Berat \\ Politeknik Negeri Balikpapan \\ Jl. Soekarno-Hatta Km.8 Balikpapan \\ E-mail: Syahruddin@poltekba.ac.id
}

\begin{abstract}
Efforts to improve the efficiency of work processes in a remanufacturing industry can be done by taking into account the layout of the work area, workers who did his job or job step sequence. Problems that occur in the workshop PT. " $\mathrm{X}$ " is the area less irregular reconditioned engine components that often overlaps execution component, the delay in the completion and execution of components that move. Of some of these, this study aims to perform rearrangement of the layout area reconditioned engine components in order to obtain the layout of work processes more efficient so that productivity can be increased. This study is an experimental research conducted on the layout work area reconditioned engine components, by comparing the layout before and after reorganized. The data collected in this study include time measurement data and images. Data were collected through observation, documentation and interview. The result is a work process efficiencies that can be achieved with the rearrangement of the layout area reconditioned engine components, namely in terms of time efficiency is $12.61 \%$ and the efficiency in terms of the number of employees is $33.33 \%$.
\end{abstract}

Keywords : Layout, Engine Components, Recondition Area, Efficiency, Work Process.

\begin{abstract}
Abstrak
Usaha untuk meningkatkan efisiensi proses kerja pada suatu industri remanufaktur dapat dilakukan dengan memperhatikan layout area kerja, pekerja yang melakukan pekerjaanya ataupun urutan langkah pekerjaannya. Permasalah yang terjadi di workshop PT. "X" adalah pada area rekondisi komponen engine kurang beraturan sehingga sering terjadi tumpang tindih pengerjaan komponen, keterlambatan dalam penyelesaiannya dan tempat pengerjaan komponen yang berpindah-pindah. Dari beberapa hal tersebut, penelitian ini bertujuan melakukan penataan ulang layout area rekondisi komponen engine agar diperoleh layout proses kerja yang lebih efisien sehingga produktivitas perusahaan dapat meningkat. Penelitian ini adalah penelitian eksperimen yang dilakukan terhadap layout area kerja rekondisi komponen engine, dengan membandingkan antara layout yang sebelum dan sesudah ditata kembali. Data yang dikumpulkan dalam penelitian ini diantaranya data pengukuran waktu dan gambar. Data dikumpulkan melalui observasi, dokumentasi dan wawancara. Hasilnya adalah efisiensi proses kerja yang dapat dicapai dengan penataan ulang layout area rekondisi komponen engine yaitu dari segi efisiensi waktu adalah 12,61\% dan dari segi efisiensi jumlah pekerjanya adalah $33,33 \%$.
\end{abstract}

Kata Kunci : Layout, area rekondisi, komponen engine, efisiensi, proses kerja. 


\section{Pendahuluan}

Untuk meningkatkan efisiensi proses kerja pada suatu industri manufaktur (perusahaan rekondisi komponen-komponen pada sistem alatalat berat) dapat dilakukan dengan memperhatikan layout area kerja, pekerja yang melakukan pekerjaanya ataupun urutan langkah pekerjaannya serta keamanan dan kenyamanan pekerja.

Dalam proses produksi engine di PT. "X" ada beberapa langkah kerja yang harus dilalui yaitu, disassembly, rekondisi, assembly, running test, dan yang terakhir painting packing. Salah satu langkah kerja yang berhubungan langsung dengan komponen-komponen penting dari sebuah engine adalah proses rekondisi.

Rekondisi adalah memperbaiki atau mengembalikan penampilan atau performa suatu produk pada keadaan yang hampir sama atau mirip dengan yang baru. Rekondisi ini dilakukan dengan cara melakukan perbaikan di bagian yang terjadi kerusakan dan mengganti komponen jika lifetime komponen tersebut sudah habis atau jika komponen tersebut tidak dapat diperbaiki. Hal ini menyebabkan proses rekondisi sangat berpengaruh pada produktivitas perusahaan. Proses rekondisi memerlukan tata letak area kerja atau tempat kerja yang nyaman serta aman untuk mencapai efektifitas pengerjaan suatu komponen engine. Oleh sebab itu sangat diperlukannya tata letak area kerja yang tepat agar proses produksi perusahaan ini dapat terus bekembang.

Tata letak area kerja merupakan suatu bentuk usaha pengaturan penempatan peralatan dan komponen di area kerja serta penempatan suatu proses pengerjaan komponen, sehingga area kerja tersebut tertata dan memenuhi persyaratan-persyaratan untuk beroperasi. Masalah yang terdapat pada area kerja rekondisi yaitu kurang beraturan atau tidak tersistem dengan baik dan benar. Pengerjaan komponen juga sering kali berpindah-pindah, sehingga waktu untuk menyelesaikan pekerjaan menjadi lebih panjang dan berdampak pada keterlambatan penyelesaian pekerjaan. Hal ini juga berpengaruh pada ketidaknyamanan pekerja dan efektifitas pekerjaan serta resiko terjadinya kecelakaan menjadi lebih besar.

Berdasarkan uraian-uraian di atas, maka dapat diperoleh rumusan masalah sebagai berikut :

1. Bagaimanakah cara perbaikan area rekondisi komponen engine di workshop PT. "X" agar berjalan dengan efisien?

2. Berapakah efisiensi proses kerja yang dapat dicapai dengan penataan ulang layout area rekondisi komponen engine di workshop PT. "X"?

\section{Metode Penelitian}

Penelitian ini adalah penelitian eksperimen yang dilakukan terhadap layout area kerja rekondisi komponen engine, dengan membandingkan antara layout yang sebelum dan sesudah ditata kembali (reposisi). Penelitian ini juga membahas bagaimana cara atau upaya apa yang harus dilakukan untuk meminimalisir dampak yang ditimbulkan dari tidak teraturnya area kerja rekondisi tersebut. Data yang dikumpulkan dalam penelitian ini diantaranya data pengukuran waktu dan gambar. Data dikumpulkan melalui observasi, dokumentasi dan wawancara. Pengumpulan data dilaksanakan pada bulan Nopember sampai Desember 2014. Penulis membuat diagram alir metoda penelitian seperti pada gambar 2.1. berikut ini: 


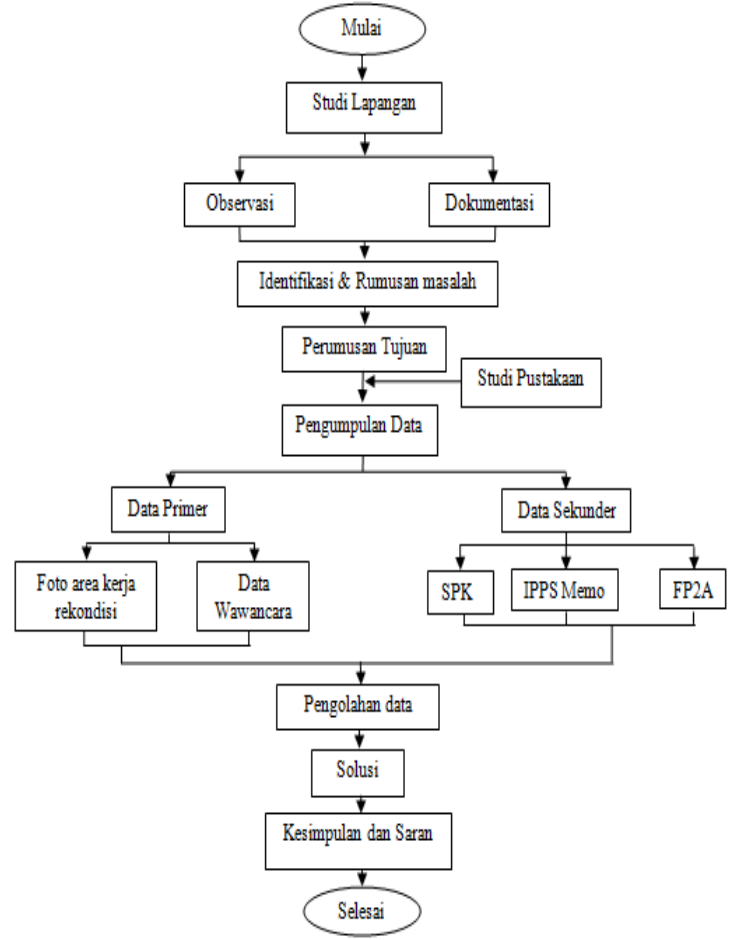

Gambar 2.1. Diagram Alir Metode Penelitian

\section{Hasil dan Pembahasan}

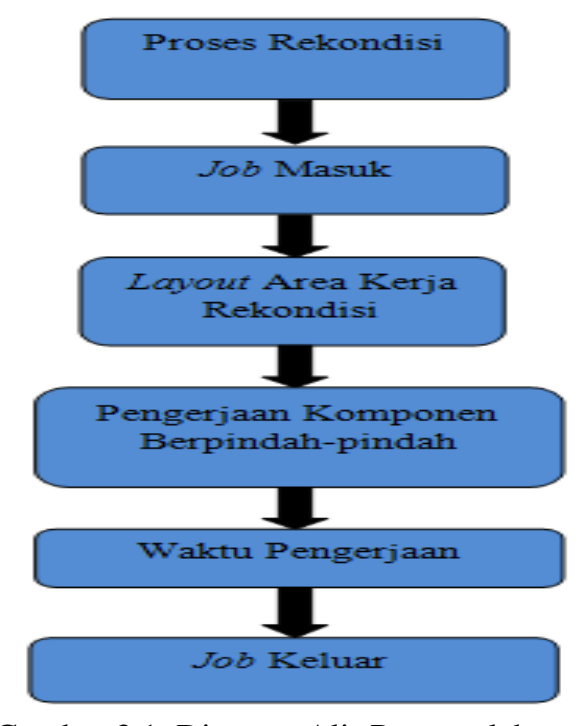

Gambar 3.1. Diagram Alir Permasalahan

Permasalahan yang ditemukan oleh penulis terdapat di area kerja rekondisi. Dengan layout area kerja yang sekarang pekerjaan rekondisi sering kali berpindah-pindah, sehingga waktu yang digunakan untuk semua pekerjaan rekondisi menjadi kurang efisien. Hal ini berpengaruh pada rasa nyaman dan aman bagi pekerja, waktu pengerjaan serta pada job keluar. Semakin sering mekanik melakukan perpindahan tempat pada saat melakukan suatu pekerjaan, maka waktu yang dibutuhkan untuk menyelesaikan pekerjaan menjadi lebih panjang, sehingga berpengaruh pada penyelesaian suatu job tidak sesuai dengan waktu yang telah ditentukan atau terlambat. Dari permasalahan ini penulis membuat layout yang memungkinkan perusahaan meminimalisir permasalahan tersebut. Penulis merancang sebuah layout yang mengurangi terjadinya perpindahan tempat pada saat pekerja melakukan suatu pekerjaan, dengan berkurangnya permasalahan tersebut waktu yang dibutuhkan untuk menyelesaikan suatu pekerjaan akan lebih efisien dan efektifitas kerja dapat tercapai.

Layout area kerja ini juga dibuat untuk mengurangi terjadinya kecelakaan pada saat bekerja maupun kecelakaan yang bisa terjadi pada komponen yang dikerjakan, sehingga para mekanik merasa lebih nyaman juga aman bekerja dengan layout area kerja yang dibuat oleh penulis. Di bawah ini adalah gambar layout area kerja rekondisi sebelum penataan dan juga terdapat layout area kerja rekondisi setelah penataan. Area kerja rekondisi ini berukuran $4 \mathrm{~m} \times 5 \mathrm{~m}$, dengan jumlah mekanik sebanyak 6 orang. Untuk 1 job engine yang akan direkondisi ditangani oleh 3 orang mekanik, dan 1 job engine terdiri dari 6 komponen yang harus diselesaikan dalam waktu 6 hari. Dapat dilihat pada gambar 3.3, terdapat 2 buah stand komponen engine ready (yang sudah siap untuk dipasang) ditandai dengan A1 dan A2; 1 buah meja tempat komponen dan 2 buah meja kerja yang dirapatkan ditandai dengan B1, B2 dan B3; 2 buah stand komponen engine 
ditandai dengan $\mathrm{C} 1$ dan $\mathrm{C} 2 ; 2$ buah toolbox ditandai dengan D1 dan D2; dan 3 buah toolbox flexible yang diletakan secara horizontal ditandai dengan E1, E2 dan E3. Di sebelah kanan (dilihat dari atas) adalah tempat komponen masuk, komponen tersebut diletakkan pada meja kerja bahkan sampai meja kerja tempat komponen ready atau komponen keluar disebelah kiri. Dengan layout seperti ini menyebabkan pekerjaan para mekanik tidak beraturan, ini berdampak pada proses pengerjaan yang berpindahpindah tempat.

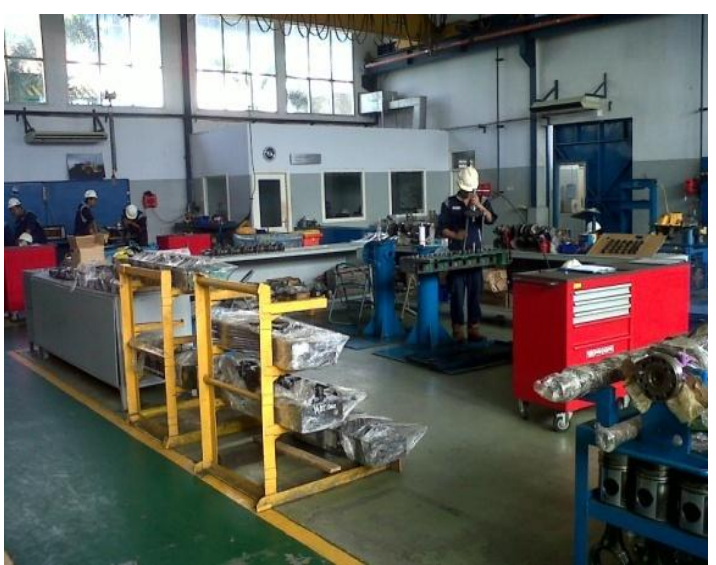

Gambar 3.2. Area Kerja Rekondisi

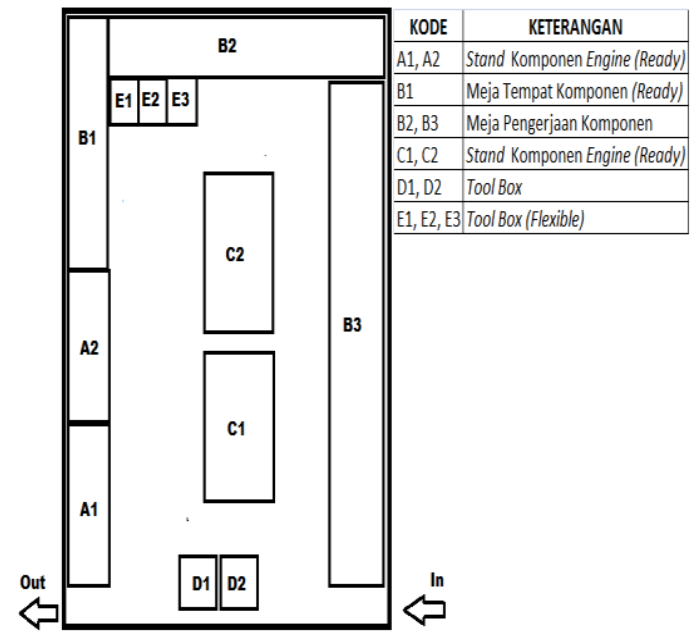

Gambar 3.3 Layout Area Kerja Rekondisi Sebelum Penataan

Di bawah ini adalah gambar layout area kerja rekondisi setelah penataan.

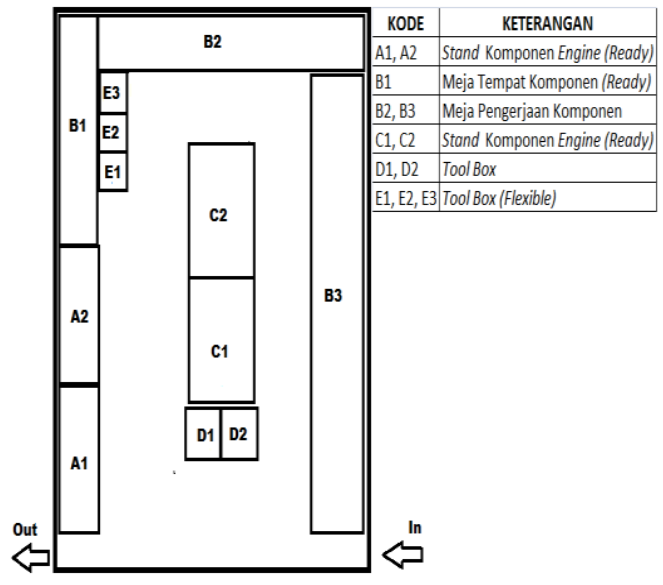

Gambar 3.4. Layout Area Kerja Rekondisi Setelah Penataan

Dari gambar 3.4 di atas terlihat 2 buah stand komponen engine yang sudah siap untuk dipasang atau ready ditandai dengan A1 dan A2; 1 buah meja tempat komponen dan 2 buah meja kerja yang dirapatkan ditandai dengan B1, B2 dan $\mathrm{B} 3 ; 2$ buah stand komponen engine ditandai dengan $\mathrm{C} 1$ dan $\mathrm{C} 2 ; 2$ buah toolbox ditandai dengan D1 dan D2; dan 3 buah toolbox flexible yang diletakan secara vertikal ditandai dengan E1, E2 dan E3. Pada sisi atas tepatnya pada meja B2 dan B3 sebelah kanan adalah tempat menaruh komponen masuk, hanya komponen masuk yaitu komponen yang akan dikerjakan oleh mekanik. Sedangkan pada meja komponen B1 adalah tempat menaruh komponen yang siap atau ready untuk dipasang atau assembly. Tujuan diletakkannya toolbox flexible secara vertikal agar tidak menyulitkan pekerja menggeser-geser toolbox pada saat melakukan pekerjaan di meja kerja B2 agar waktu pengerjaan lebih efisien dan efektifitas kerja dapat tercapai. Perbandingan waktu antara kedua layout ini terlihat pada table 3.1 di bawah ini : 
Tabel 3.1. Tabel Perbandingan Waktu Pengerjaan dan Jumlah Pekerja Sebelum dan Setelah Penataan

\begin{tabular}{|c|c|c|c|c|c|}
\hline \multirow[b]{3}{*}{ No. } & \multirow{3}{*}{$\begin{array}{c}\text { Pekerjaan } \\
\text { Rekondisi } \\
\text { Komponen } \\
\text { Engine }\end{array}$} & \multicolumn{4}{|c|}{ Layout Area Rekondisi } \\
\hline & & \multicolumn{2}{|c|}{ Sebelum Penataan } & \multicolumn{2}{|c|}{ Setelah Penataan } \\
\hline & & \begin{tabular}{|c|} 
Waktu \\
Pengerjaan \\
Jam (j) dan \\
Menit (m)
\end{tabular} & $\begin{array}{l}\text { Jumlah } \\
\text { Pekerja }\end{array}$ & \begin{tabular}{|c|} 
Waktu \\
Pengerjaan \\
Jam (j) dan \\
Menit (m) \\
\end{tabular} & $\begin{array}{l}\text { Jumlah } \\
\text { Pekerja }\end{array}$ \\
\hline 1 & $\begin{array}{l}\text { Cylinder } \\
\text { Block }\end{array}$ & $20 \mathrm{j} 50 \mathrm{~m}$ & 3 orang & $19 \mathrm{j}$ & 2 orang \\
\hline 2 & $\begin{array}{l}\text { Cylinder } \\
\text { Head }\end{array}$ & $11 \mathrm{j} 10 \mathrm{~m}$ & 3 orang & $9 \mathrm{j} 40 \mathrm{~m}$ & 2 orang \\
\hline 3 & Crankshaft & $4 \mathrm{j} 20 \mathrm{~m}$ & 3 orang & $3 \mathrm{j} 30 \mathrm{~m}$ & 2 orang \\
\hline 4 & Camshaft & $3 \mathrm{j} 10 \mathrm{~m}$ & 3 orang & $3 \mathrm{j}$ & 2 orang \\
\hline 5 & $\begin{array}{l}\text { Connecting } \\
\text { Rod }\end{array}$ & $3 \mathrm{j} 15 \mathrm{~m}$ & 3 orang & $2 \mathrm{j} 40 \mathrm{~m}$ & 2 orang \\
\hline 6 & Piston & $2 \mathrm{j} 50 \mathrm{~m}$ & 3 orang & $2 \mathrm{j}$ & 2 orang \\
\hline & $\begin{array}{l}\text { tal Waktu \& } \\
\text { rata Pekerja }\end{array}$ & $45 \mathrm{j} 35 \mathrm{~m}$ & 3 orang & $39 \mathrm{j} 50 \mathrm{~m}$ & 2 orang \\
\hline
\end{tabular}

Sumber: Pengolahan Data

Dari tabel di atas perbandingan waktu pengerjaan dengan menggunakan layout area kerja sebelum penataan dan layout area kerja setelah penataan. Waktu yang dibutuhkan untuk menyelesaikan 1 job dengan layout area kerja sebelum penataan adalah sekitar 45 jam 35 menit yaitu dalam 6 hari (dengan jumlah jam kerja per hari adalah 8), sedangkan dengan layout area kerja setelah penataan adalah sekitar 39 jam 50 menit yaitu dalam 5 hari. Selain itu dapat dilihat juga jumlah pekerja yang dibutuhkan dengan layout area kerja sebelum penataan adalah 3 orang, dan dengan layout area kerja setelah penataan adalah 2 orang. Selisih waktu antara layout area kerja sebelum penataan dan layout area kerja setelah penataan adalah 5 jam 45 menit dengan selisih jumlah pekerja 1 orang. Setelah penataan ulang layout rekondisi komponen engine, maka efisiensi waktu yang dihasilkan adalah $12,61 \%$ dan efisiensi jumlah pekerjanya adalah $33,33 \%$.

\section{Kesimpulan}

Berdasarkan pengolahan dan analisis data yang dilakukan, maka dapat disimpulkan bahwa:

1. Cara memperbaiki area rekondisi komponen engine adalah dengan melakukan penataan kembali posisi tempat kerja, mulai dari tempat meletakkan komponen masuk sampai komponen keluar dengan mempertimbangkan aspek waktu kerja, beban kerja, kenyamanan dan keamanan pekerjaan sehingga efisiensi proses kerja dapat tercapai.

2. Efisiensi proses kerja yang dapat dicapai dengan penataan ulang layout area rekondisi komponen engine yaitu: dari segi efisiensi waktu yang dihasilkan adalah $12,61 \%$ dan dari segi efisiensi jumlah pekerjanya adalah $33,33 \%$.

\section{Saran}

Perusahaan disarankan untuk selalu menggunakan layout area kerja rekondisi yang telah dirancang agar efisiensi proses kerja dapat tercapai. Selain itu perlu perluasan area kerja dengan menambah stand komponen engine agar bisa mengerjakan 2 job atau lebih untuk meningkatkan produktifitas.

\section{Ucapan Terima Kasih}

Terimakasih ditujukan kepada manager PT "X" Balikpapan yang telah menyediakan tempat untuk pelaksanaan penelitian ini.

\section{Daftar Pustaka}

Apple, J. M., 1977, Plant Layout and Material Handling., $3^{\text {rd }}$ ed., John Wiley $\&$ Sons: new York.

Francis, Richard. L, MacGinnis, Leon Franklin, White, John A., 1992., Facility Layout and Location : An Analytical Approach, $2^{\text {nd }}$ ed., Prentice Hall 
Harianto, Dinda Puspita Mandiri, 2010, Analisis Tata Letak Fasilitas (Studi Kasus UKM Sandal AMORITA'S), Universitas Gunadarma Depok.

Hari Purnomo, 2004. Perencanaan dan Perancanagan Fasilitas. Graha Ilmu, Yogyakarta.

Koes Sulistiadji, 1982, Manajemen Bengkel, Subdit Mekanisasi, Dit. Bina Produksi, Tan. Pangan, Ditjentan, Deptan
Kotler, Philip, 1995, Manajemen Pemasaran, Jilid 1 dan Jilid 2, Penerbit Erlangga, Jl. H. Baping Raya No. 100 Ciracas, Jakarta 13740.

Muther, Richard, 1974, Schematic Layout Planning $2^{\text {nd }}$ ed. Cahners Book, Boston.

Sritomo Wignjosoebroto, 2009, Tata Letak Pabrik dan Pemindahan Bahan, Edisi Ketiga, Penerbit Guna Widya, Jakarta. 